\title{
Investigations on tri manganese tetra oxide nano particles prepared by thermal decomposition
}

\author{
C. Sagi Rani ${ }^{1}$, P. Athira ${ }^{1}$, N. Joseph John ${ }^{2}$ \\ ${ }^{1}$ Department of Physics, Noorul Islam Centre for Higher Education, Noorul Islam University, \\ Kumaracoil, Tamil Nadu, India \\ ${ }^{2}$ Department of Physics, Govt. Arts College, The Nilgris, Tamil Nadu, India \\ sagirani.c@gmail.com, athira01011993@gmail.com
}

\begin{abstract}
Oxides of manganese have large number of applications in the field of sensors, piezoelectric crystals etc. In the present work, $\mathrm{Mn}_{3} \mathrm{O}_{4}$ nano materials were synthesized by using manganese acetate, adopting the method of thermal decomposition. The Nano materials thus prepared were characterized by employing various techniques like PXRD, FTIR, UV and Thermal analyses. The average particle size, calculated using Debye-Scherrer formula, was found to be in the range of $51-62 \mathrm{~nm}$. The presence of $\mathrm{Mn}_{3} \mathrm{O}_{4}$ is also confirmed from FTIR. Thermal studies were also carried out. The optical band gap for the prepared nano materials was obtained from the UV-spectroscopic studies.
\end{abstract}

Keywords: Nano particles, thermal decomposition, PXRD, FTIR, UV, thermal studies.

Received: 5 February 2016. Revised: 31 May 2016.

\section{Introduction}

Nanotechnology provides the ability to create new materials or devices with new functions and properties. The current age is characterized by increased technological advances and rapid nanotechnology development [1]. Technologies with such a system of materials having at least one of its dimensions within $100 \mathrm{~nm}$ are referred to as nanoscience. The fundamental, physical, chemical and natural properties of materials are considerably altered as the size of their consistent grains is decreased to the nanometer scale. Most of the nanostructured materials have properties significantly different from those of the bulk materials due to the factors such as large fraction of surface atoms, high surface energy and reduced imperfections [2,3].

It is evident that nanostructured materials are expected to have improved optical properties compared with bulk materials, as these properties depend on their size, shape and local dielectric environment [4]. In recent years, the synthesis of semiconductor materials with specific size and morphology has attracted a lot of interest due to their significant mechanical, electrical, optical and magnetic properties for potential applications in various fields [5]. Nanoscience and nanotechnology find applications in almost every branch of science and technology, electronics, astrophysics and in medical science. Recent progress in the preparation and characterization of materials on nanometer scale has introduced a new point of view for scientists in reduced dimensions. This will change the crystalline and electronic structure considerably [2].

Transition metal oxide nanoparticles are very attractive due to their variety of applications [6]. $\mathrm{Mn}_{3} \mathrm{O}_{4}$ is an important transition metal oxide due to its extensive applications in magnetic, electrochemical, lithium ion batteries, catalytic applications, super capacitors and dilute magnetic semiconductors etc. [7]. It is one of the most stable oxides of manganese [6]. Due to its nanometer size and large surface area, different morphologies are expected to display better performance in all the above mentioned applications [6]. The optical properties are the most fascinating and very useful properties of nano metal oxides. Oxides of manganese have optical properties which are associated with the intrinsic and extrinsic effect. The optical transition between the electrons in the conduction band and holes in the valence band causes the intrinsic effect. $\mathrm{Mn}_{3} \mathrm{O}_{4}$ is a direct band gap semiconductor and a transparent conducting material. By using a large number of techniques such as optical absorption, photo-reflection, photoluminescence etc. the optical transitions can be widely used in variety of applications.

In the present study, $\mathrm{Mn}_{3} \mathrm{O}_{4}$ nanoparticles were prepared using the thermal decomposition technique. Manganese oxide nanoparticles are water insoluble, brownish black powder and have no odor. $\mathrm{Mn}_{3} \mathrm{O}_{4}$ has the spinel structure [3], where the oxide ions are cubically closed packed and the $\mathrm{Mn}^{\mathrm{II}}$ ions occupy tetrahedral sites whereas the $\mathrm{Mn}^{\mathrm{III}}$ occupy the octahedral sites $[3,7]$. 


\section{Experimental procedure}

Tri manganese tetra oxide nanoparticles were prepared by adopting the method of thermal decomposition. The required quantity of manganese acetate tetra hydrate $\left[\left(\mathrm{CH}_{3} \mathrm{COO}\right)_{2} \mathrm{Mn} \cdot 4 \mathrm{H}_{2} \mathrm{O}\right]$ in its dry form is taken in a ceramic container and is heated in a muffle furnace for a period of $24 \mathrm{hrs}$, maintained at a temperature of $950{ }^{\circ} \mathrm{C}$. As a result, a brownish black powder of $\mathrm{Mn}_{3} \mathrm{O}_{4}$ particles was obtained and collected for further characterization.

\section{Result and discussion}

\subsection{XRD characterization}

The prepared $\mathrm{Mn}_{3} \mathrm{O}_{4}$ nanomaterials were characterized by powder X-ray diffraction. X-ray powder diffraction measurements were performed using the X-ray diffractometer operating with $\mathrm{Cu}-\mathrm{K} \alpha$ radiation $(\lambda=0.15406 \mathrm{~nm})$. Fig. 1 shows the X-ray diffraction spectra for the prepared $\mathrm{Mn}_{3} \mathrm{O}_{4}$ nanoparticles.

Figure 1 shows the crystalline structure with several significant peaks that can be readily indexed as (112), (200), (103), (211), (004), (220), (105), (224), (312) and (400) crystal planes respectively, which is in good agreement with the standard value, JCPDS No. 024-0734. All the peaks in the pattern can be indexed to a tetragonal phase with lattice constants $a=b=5.7621 \AA, c=9.4696 \AA$.

The particle size is calculated according to Debye-Scherrer formula:

$$
2 d=\frac{0.9 \lambda}{\beta \cos \theta},
$$

where $\lambda$ is the wave length of $\mathrm{Cu}-\mathrm{K} \alpha$ radiation, $\beta$ is the full width at half maximum, corresponding to the diffraction angle $2 \theta$. The crystal size for the prepared $\mathrm{Mn}_{3} \mathrm{O}_{4}$ nano particle was found to be $51-62 \mathrm{~nm}$.

\subsection{FTIR characterization}

Figure 2 shows the FTIR spectra of the prepared $\mathrm{Mn}_{3} \mathrm{O}_{4}$ nano particles which show several significant absorption peaks that help to understand various chemical bonds present in it.

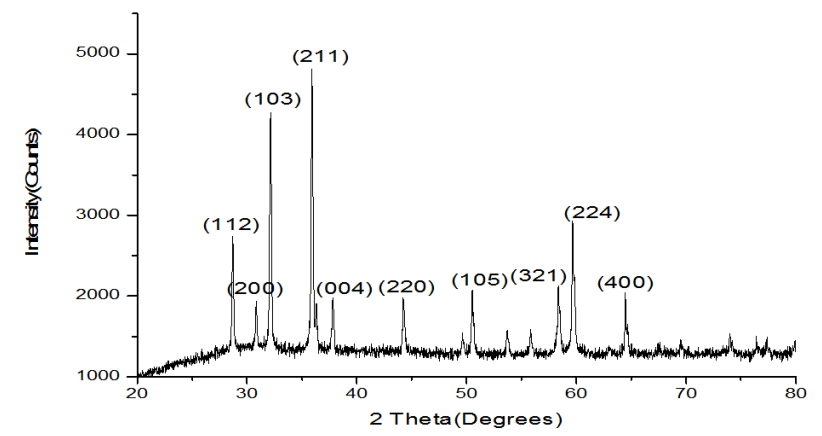

FIG. 1. XRD Spectra for the prepared $\mathrm{Mn}_{3} \mathrm{O}_{4}$ nano particles

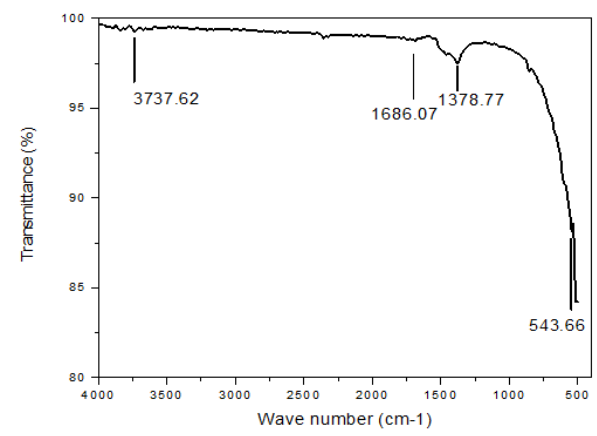

FIG. 2. FTIR Spectra for the prepared $\mathrm{Mn}_{3} \mathrm{O}_{4}$ nano particle

The vibration frequency located at $543 \mathrm{~cm}^{-1}$ corresponds to the vibration of Mn-O stretching modes. Moreover, the broad band at $3738 \mathrm{~cm}^{-1}$ and the narrow one at $1666 \mathrm{~cm}^{-1}$ correspond to $\mathrm{O}-\mathrm{H}$ vibrating mode of the adsorbed water. Thus, FTIR provides concrete evidence for the presence of manganese oxide.

\subsection{Thermal analysis (TGA/DTA)}

The thermal stability of the prepared $\mathrm{Mn}_{3} \mathrm{O}_{4}$ nano particles was carried out between $250-1050{ }^{\circ} \mathrm{C}$.

Figure 3 represent the TGA/DTA spectra for the prepared $\mathrm{Mn}_{3} \mathrm{O}_{4}$ nano particles. In the temperature range up to $300{ }^{\circ} \mathrm{C}$ a weight loss of $2.85 \%$ can be related to the release of weakly adsorbed water molecules. It is found that the sample was completely decomposed within the given range.

\subsection{UV characterization}

The UV absorption spectra for the prepared $\mathrm{Mn}_{3} \mathrm{O}_{4}$ nano particle is shown in Fig. 4. The optical absorption peak intensity was found to be $316.507 \mathrm{~nm}$. The optical band gap of the sample is calculated using the formula, $E_{g}=h c / \lambda$, where $E_{g}$ - energy gap, $c$ - velocity of light and $\lambda$ - wave length. The optical band gap for the prepared $\mathrm{Mn}_{3} \mathrm{O}_{4}$ nano particle was found to be on the order of $3.824 \mathrm{eV}$. 


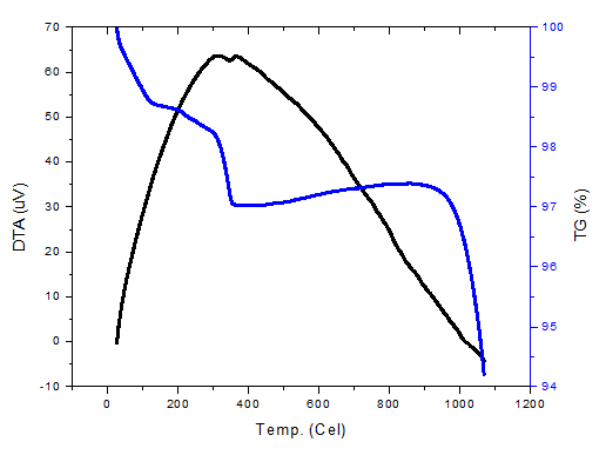

FIG. 3. TGA/DTA Spectra for the prepared $\mathrm{Mn}_{3} \mathrm{O}_{4}$ nano particle

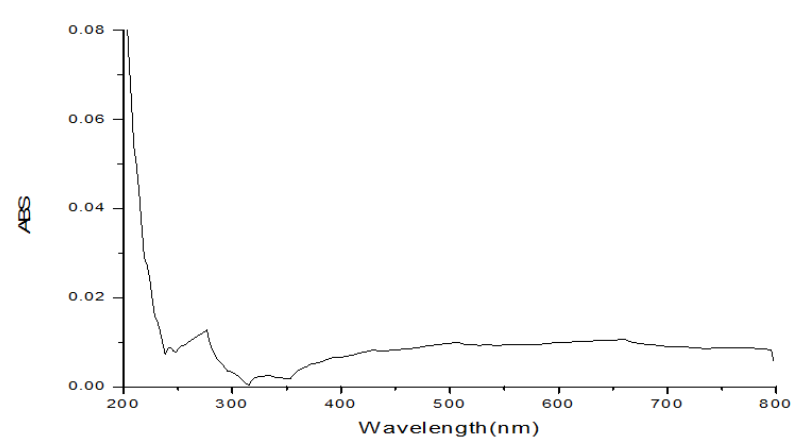

FIG. 4. UV Spectra for the prepared $\mathrm{Mn}_{3} \mathrm{O}_{4}$ nano particles

\section{Conclusions}

$\mathrm{Mn}_{3} \mathrm{O}_{4}$ nano particles were successfully synthesized by using manganese acetate by adopting the method of thermal decomposition. The nano materials thus prepared were characterized by adopting various techniques like XRD, FTIR, UV and thermal analysis. The average particle size is calculated using Debye-Scherrer formula as $56 \mathrm{~nm}$. Presence of $\mathrm{Mn}_{3} \mathrm{O}_{4}$ is also confirmed from FTIR. Thermal studies were also carried out. The optical band gap for the prepared nanomaterials was found to be $3.824 \mathrm{eV}$.

\section{Acknowledgements}

We would like to acknowledge The University of Kerala X-RD Laboratory (DST-PURSE) Kariavattom Campus, Trivandrum for the XRD characterization. The facilities provided by the research laboratories of Department of Physics as well as the department of Nanotechnology, Noorul Islam Centre for Higher Education were also greatly acknowledged.

\section{References}

[1] Shanmugam S. Nanotechnology, MJP publishers. 2011.

[2] Usha K., Mahadevan C.K. Structure, Morphology and Electrical properties of $\mathrm{Mn}_{3} \mathrm{O}_{4}$ nanocrystals. Scholars Research Library, Archives of Physics Research, 2011, 2 (1), P. 75-80.

[3] Sherin J.S., Thomas J.K., Suthagar J. Combustion Synthesis and Magnetic Studies of Hausmannite, $\mathrm{Mn}_{3} \mathrm{O}_{4}$, nanoparticles. International Journal of Engineering Research and Development, 2014, 10 (7), P. 34-41.

[4] Hassouna Dhaouadiet, Hassouna Dhaouadi, et al. $\mathrm{Mn}_{3} \mathrm{O}_{4}$ Nanoparticles: Synthesis, Characterization, and Dielectric Properties. International Scholarly Research Network Spectroscopy, 2012, Article ID 706398, 8 p.

[5] Mote V.D., Dargad J.S., Dole B.N. Effect of Mn doping concentration on structural, Morphological and optical studies of ZnO NanoParticles. Nanoscience and Nano engineering, 2013, 1 (2), P. 116-122.

[6] Vijaya Lakshmi S., Pauline S., Maria Vinosel V. Microstructural Characteriztion of Trimanganese Tetra Oxide $\left(\mathrm{Mn}_{3} \mathrm{O}_{4}\right) \mathrm{Nanoparticle}$ by Solvothermal Method and Its Dielectric Studies. International journal of engineering sciences \& research technology, 2014, 3 (11), P. $123-131$.

[7] Shrividhya T., Ravi G., Mahalingam T., Hayakawa Y. Synthesis and Study on Structural, Morphological and Magnetic properties of nanocrystalline Manganese Oxide. International Journal of Science and Engineering Applications, Special Issue NCRTAM ISSN-23197560, 2013. DOI: 10.7753/IJSEANCRTAM.1004.

[8] Harish Kumar, Manisha, Poonam Sangwan. Synthesis and Characterization of $\mathrm{MnO}_{2}$ Nanoparticles using Co-precipitation Technique. International Journal of Chemistry and Chemical Engineering, 2013, 3 (3), P. 155-160.

[9] Wang Z.H., Geng D.Y., et al. Magnetic properties and exchange bias in $\mathrm{Mn}_{2} \mathrm{O}_{3} / \mathrm{Mn}_{3} \mathrm{O}_{4}$ nanoclusters. Journal of applied physics, 2009, 105, 07A315.

[10] Yanyan Yang, Lifen Xiao, Yanqiang Zhao, Fengyun Wang. Hydrothermal Synthesis and Electrochemical Characterization of $\alpha-\mathrm{MnO}_{2}$ Nanorods as Cathode Material for Lithium Batteries. Int. J. Electrochem. Sci., 2008, 3, P. 67-74.

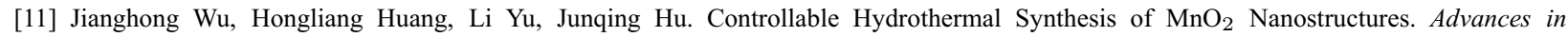
Materials Physics and Chemistry, 2013, 3 (3), P. 201-205.

[12] Pradeep Kumar B.M., Shivaprasad K.H., et al. Preparation of $\mathrm{MnO}_{2}$ nanoparticles for the adsorption of environmentally hazardous malachite green dye. International Journal of Application or Innovation in Engineering \& Management (IJAIEM), 2014, 3 (12), P. 102106.

[13] Hansung Kim, Branko N. Popov. Synthesis and Characterization of $\mathrm{MnO}_{2}$-Based Mixed Oxides as Super capacitors. Journal of the Electrochemical Society, 2003, 150 (3), D56-D62.

[14] Hiromichi Hayashi, Yukiya Hakuta. Hydrothermal Synthesis of Metal Oxide Nanoparticles in Supercritical Water. Materials, 2010, 3, P. $3794-3817$.

[15] Edelsten A.S., Cammarata R.C. Nanomaterials synthesis properties and applications. Novel research laboratory, Washington, 1988. 